\title{
O PROGRAMA INSTITUCIONAL DE BOLSAS DE INICIAÇÃO À DOCÊNCIA (PIBID) E A "PERFORMANCE" ESCOLAR
}

\author{
Marcio Issler ${ }^{1}$, Adrian Alvarez Estrada ${ }^{2}$, Ieda Maria Kleinert Casagrande ${ }^{3}$
}

\begin{abstract}
Resumo: $\mathrm{O}$ artigo em questão objetiva analisar os desdobramentos do Programa Institucional de Bolsas de Iniciação à Docência (PIBID) para a formação inicial de professores. Os dados coletados versam sobre publicações nacionais e produções internacionais acerca da "performatividade" na área educacional. A abordagem compreende o desempenho dos sujeitos ou organizações que servem de parâmetros de produtividade ou demonstrações de "qualidade", como cultura ou forma de regulação, comparações e incentivos, pautados em recompensas e sanções materiais e simbólicas. Corrobora a abordagem o PIBID, quando refere à função de "elevar a "qualidade" da formação inicial de professores nos cursos de licenciatura, promovendo a integração entre educação superior e educação básica". A "performance" voltada à formação de professores no caso do PIBID se caracteriza como tema central para elevar a "qualidade" com o intuito de compreender de qual "qualidade" se fala, pois, na educação, produtividade e rendimento acabam sendo traduzidos na forma de desempenho, ou seja, em performance.
\end{abstract}

Palavras-chave: Formação de Professores. Programa Institucional de Bolsas de Iniciação à Docência. Performatividade. Qualidade.

\section{INSTITUTIONAL SCHOLARSHIP PROGRAM FOR INITIATION IN TEACHING AND SCHOOL PERFORMATIVITY}

Abstract: The article in question aims to analyze the developments of the Institutional Program of Initiation to Teaching Grant (PIBID) for the initial formation of teachers. The collected data are about national publications and international productions about "performativity" in the educational area. The approach comprises the performance of subjects or organizations that serve as productivity parameters

1 Graduado em Pedagogia - UNIOESTE; Mestrando em Educação da Universidade Estadual do Oeste do Paraná - UNIOESTE - Campus de Cascavel - PR. Bolsista CAPES/ FUNDAÇÃO ARAUCÁRIA. E-mail: marcioissler@hotmail.com

2 Doutor em Educação pela Universidade de São Paulo - USP; Docente do Colegiado do Curso de Pedagogia e do Mestrado em Educação da UNIOESTE - Campus de Cascavel - PR. E-mail: adrianalvarez.estrada@gmail.com

3 Doutora em Educação-UFSM. Bolsista PNPD/CAPES - Universidade Estadual do Oeste do Paraná/ Unioeste. E-mail: iedakleinert@gmail.com. 
or demonstrations of "quality", such as culture or form of regulation, comparisons and incentives, based on material and symbolic rewards and sanctions. It corroborates the PIBID approach, when it refers to the function of "raising the quality" of initial teacher training in undergraduate courses, promoting the integration between higher education and basic education. The "performance" aimed at teacher training in the case of PIBID is characterized as a central theme to raise "quality" in order to understand what "quality" is spoken, since education, productivity and income end up being translated into the form performance.

Keywords: Teacher training. Institutional Program of Initiation to Teaching Scholarship. Performativity. Quality.

\section{INTRODUÇÃO}

A temática da formação de professores é um fenômeno complexo e multifacetado, alicerçado sobre várias conceitualizações e com pouco consenso em relação às suas definições e às teorias mais relevantes para sua análise. Nota-se, em um primeiro momento, a necessidade de um quadro teórico e conceitual orgânico que possibilite um esclarecimento e ordene, ao mesmo tempo, essa área do conhecimento (LIMA, 2007, p. 38).

O texto apresenta parte das reflexões de um projeto de pesquisa em educação em andamento e tem como objetivo principal oportunizar discussões a respeito da performatividade do ensino e suas relações com a qualidade educacional. Para tanto, considera o Programa Institucional de Bolsas de Iniciação à Docência (PIBID), uma política educacional brasileira que concede bolsas para alunos de Licenciaturas de Instituições de Ensino Superior e visão aperfeiçoamento da formação de professores para a educação básica, a valorização dos futuros professores durante o processo de formação e a qualidade da educação pública brasileira. Foi criado em 2007 e regulamentado pelo Decreto n ${ }^{\circ} 7219 / 2010$, tornando-se uma política de Estado e programa permanente do Ministério da Educação (MEC) em 04 de abril de 2013. (BRASIL, 2006).

A análise documental toma como referência o descritor "qualidade" para avaliar de qual "qualidade" se refere, pois, na educação, produtividade e rendimento acabam sendo traduzidos na forma de desempenho, ou seja, em performance.

Assim, por meio do estudo deixa-se de lado os slogans, os "bordões com aura" dos discursos e documentos da política educacional (EVENGELISTA, 2014)para passar a analisar as subjetividades ali contidas, pois, os sentidos parecem não estar somente nas palavras, elas mesmas estão aquém e possivelmente além delas. $O$ desafio é repensar a prática docente, demonstrando que a formação de professores deve refletir para além da expectativa de instrumentalização e de desenvolvimento do pensamento e dos saberes práticos e concretos (pontuais) que são necessários à formação, ou mesmo, desmistificar ou desvelar os slogans sobre melhoria e qualidade do ensino. Nesse sentido, trata-se de uma perspectiva de formação de professores que enfatize tais aspectos: 
[...] deve estimular uma perspectiva crítico-reflexiva, que forneça aos professores os meios de um pensamento autónomo e que facilite as dinâmicas de auto-formação participada. Estar em formação implica um investimento pessoal, um trabalho livre e criativo sobre os percursos e os projectos próprios, com vista à construção de uma identidade, que é também uma identidade profissional (NÓVOA, 1992, p. 27).

Sob esse prisma, parece claro que a formação de professores tem ocupado lugar central no debate quando busca situar sua reflexão "para além das clivagens tradicionais [...] sugerindo novas maneiras de pensar a problemática da formação de professores" (NÓVOA, 1992, p. 23). Na busca desse sentido e de suas maneiras de conceber a problemática, insere-se o Programa Institucional de Bolsas de Iniciação à Docência (PIBID) que tem como uma das finalidades a melhoria da formação docente.

\title{
2 QUALIDADE EDUCACIONAL E PERFORMATIVIDADE EM PAUTA
}

Nos últimos anos a educação e o ensino estão sob a égide de realizações materiais e institucionais que em alguma medida envolvem a performatividade. Escolas precisam ter um bom desempenho, mostrar que são eficazes, que sabem investir o dinheiro recebido e que foi usado eficazmente, tendo resultados visíveis e adequados. Cada vez mais a educação passa a ser considerada a partir de sua performance.

O conceito de performatividade trabalhado nesse texto baseia-se nos pressupostos de Stephen Ball e compreende que a,

\begin{abstract}
A performatividade é uma tecnologia, uma cultura e um método de regulamentação que emprega julgamentos, comparações e demonstrações como meios de controle, atrito e mudança. Os desempenhos de sujeitos individuais ou de organizações servem de parâmetros de produtividade ou de resultado, ou servem ainda como demonstrações de "qualidade" ou "momentos" de promoção ou inspeção (BALL, 2005, p. 543).
\end{abstract}

Sob essa perspectiva a eficiência e eficácia, bem como qualidade, passam a ser preocupações-chave para os professores, que diariamente são confrontados frente à listas intermináveis de competências básicas, as quais os estudantes devem alcançar.

Em meio a estas preocupações, surgem novas metodologias e ferramentas, que intentam mesurar a gestão e avaliação dos alunos, de forma que sirvam ao que aqui nomeamos de performatividade, de modo a ocultar as diferenças, exigindo que tudo passe a ser mensurável em relação a todo o resto, para que tudo possa ser classificado segundo uma forma, o que implica por vezes a desvalorização daquilo que não pode ser classificado. 
Se a performatividade é uma tecnologia, uma cultura e um modo de regulação conforme exposto anteriormente, qualidade, ou ainda, momento de produção, conforme exposto por Ball, (2005), a performatividade se justifica justamente pelo fato de procurar a qualidade educativa, afinal, quem pode ser contra a qualidade na educação?

Dessa forma, é possível falar e agir em educação sem levar em conta a estrutura da qualidade. Contudo, ao falarmos em qualidade, em grande parte dos casos, a mesma se relaciona com padrões eficazes, o que pode, nesse sentido caracterizar-se como uma mudança em curso em relação à formação de professores, bem como dos condicionantes em relação a sua prática.

Nessa direção, quando nos referimos a performatividade em relação aos padrões eficazes na educação, compreendemos o que Lyotard (1984, apud, BALL, 2005, p. 544) refere quando a chamou de "os terrores (soft e hard) de desempenho e eficiência" o que significa: "seja operacional (ou seja, comensurável) ou desapareça".

Para o autor, a performatividade faz parte dos aspectos funcionais da modernidade, como forma de exteriorização do conhecimento em relação às possíveis transformações voltadas ao mercado de trabalho, ou seja, a qualidade da educação.

Performatividade aqui é compreendida como a construção, ou mesmo publicação de elementos indicadores, realizações materiais e institucionais de caráter promocional, que estimulem ao alcanço de resultados, mediante uma tendência de nomear, classificar e diferenciar.

Por isso, inserimos o Programa Institucional de Bolsas de Iniciação à Docência associando-o à performatividade em relação ao empenho com que tentam corresponder aos novos e os inconciliáveis "imperativos da competição e do cumprimento de metas" (BALL, 2005, p. 548).

Essencialmente, a luta pela visibilidade que o PIBID tomou nos últimos anos, para sua efetivação e implementação, o torna performático, no sentido de que procura mecanismos para que possa contribuir com a elevação da qualidade da formação inicial de professores nos cursos de licenciatura, o que por vezes se volta à fria racionalidade da performatividade que se "vincula à culpa e ao tormento de querer ser "um bom professor", frente a uma moral pública construída pela mídia, segundo a qual a mesma "se destina a difamar a "pior escola" e "professores que deixam a desejar" (BALL, 2005, p. 551).

\section{O PROGRAMA INSTITUCIONAL DE BOLSAS DE INICIAÇÃO À DOCÊNCIA}

O PIBID é um dos programas do Ministério da Educação (MEC) que tem como finalidade a melhoria da formação docente. Foi implementado em 2007, superou as expectativas e está, após cinco anos, na maioria das instituições de ensino superior 
públicas do Brasil, auxiliando na melhoria e qualidade do desenvolvimento profissional dos discentes (TOBALDINI, 2013, p. 13).

Dessa forma, é válido ressaltar que o PIBID se diferencia do "estágio supervisionado por ser uma proposta extracurricular" (JARDILINO, 2014), por ter uma carga horária diferenciada (maior) que a estabelecida pelo Conselho Nacional de Educação - CNE, bem como "por acolher bolsistas desde o primeiro semestre letivo, se assim definirem as IES em seu projeto” (CAPES, 2015, p. 64).

Portanto os bolsistas são inseridos nas escolas de forma orgânica, e não apenas com caráter de observação, como costumeiramente realizados pelos estágios.

Já em relação aos princípios norteadores do programa, e do qual partem nossos questionamentos em relação à qual qualidade ele se refere, a Portaria no 96/2013 CAPES, de 18 de julho de 2013 que tem como objetivos:

I - incentivar a formação de docentes em nível superior para a educação básica;
II - contribuir para a valorização do magistério;
III - elevar a qualidade da formação inicial de professores nos cursos de licenciatura,
promovendo a integração entre educação superior e educação básica;
IV - inserir os licenciandos no cotidiano de escolas da rede pública de educação,
proporcionando-lhes oportunidades de criação e participação em experiências
metodológicas, tecnológicas e práticas docentes de caráter inovador e
interdisciplinar que busquem a superação de problemas identificados no processo
de ensino-aprendizagem;
V - incentivar escolas públicas de educação básica, mobilizando seus professores
como coformadores dos futuros docentes e tornando-as protagonistas nos
processos de formação inicial para o magistério; e
VI - contribuir para a articulação entre teoria e prática necessárias à formação dos
docentes, elevando a qualidade das ações acadêmicas nos cursos de licenciatura.
VII - contribuir para que os estudantes de licenciatura se insiram na cultura
escolar do magistério, por meio da apropriação (CAPES,2013, grifo nosso).

De acordo com o Relatório de Gestão 2009-2014, os objetivos acima elencados partem de um reconhecimento da escola e da formação, alunos e professores que atuam na educação básica, levando em conta as diferenças, peculiaridades e características de cada qual. O "Pibid, portanto, é uma ação voltada para o humano, para as práticas educacionais que cultivem os valores sociais, éticos e estéticos da sociedade brasileira" (CAPES, 2015, p. 67).

Assim, Paredes (2012), salienta que o PIBID, tem condições de possibilitar o fortalecimento da formação inicial, pois, articula os saberes disciplinares, curriculares, oriundos da prática escolar, estimulando a formação continuada dos professores (supervisores) mediante a intensa troca de experiências, corroborando uma das finalidades do PIBID, fomento à iniciação à docência de estudantes [...] aprimorandolhes a qualidade da formação docente em curso presencial de licenciatura de graduação 
plena e contribuindo para a elevação do padrão de qualidade da Educação Básica (BRASIL, 2009, p.91 grifosnossos).

O Programa PIBID tem como função beneficiar sujeitos e instituições, na melhoria da formação profissional dos licenciandos bem como na construção de um espaço que privilegie a formação desses acadêmicos.

\section{PERCURSO METODOLÓGICO}

A definição metodológica de análise e a abordagem a partir de um descritor, têm como objetivo analisar o movimento e as relações entre performatividade e qualidade na educação básica, sobretudo no que se refere à formação inicial de professores. Tratase de uma pesquisa de cunho bibliográfico, que visa demonstrar que os discursos educacionais se constroem e se instituem a partir de palavras ou slogans e assim sendo, permitem condições para que a educação nacional se desenvolva imersa no tema implícito de sua emergência e cenário.

No caso em tela, o descritor "qualidade" foi definido e coletado em todos os parágrafos em que se fazia presente no documento escolhido para tal, ou seja, o estudo avaliativo do Programa Institucional de Bolsas de Iniciação à Docência (Pibid) produzido em 2014. Ao final, o destaque serviu como uma rede para compor a derivação de sentidos atribuídos a ela, sobre qual o tipo de qualidade é apresentada e a expressão e articulação mais precisa entre o sentido atribuído à performatividade como centralidade na busca por qualidade na educação básica.

Como forma de contraposição para a análise tradicional e sem a pretensão de cobrar dos movimentos históricos passados, busca-se compreender os movimentos de estruturação realizados pela política. $\mathrm{O}$ movimento se diluiu criando a possibilidade de identificar os elementos que o constituem e cada um destes elementos relacionados à conjuntura histórica da materialização da política pública educacional brasileira, em sua relação direta com o Programa Institucional de Bolsas de Iniciação à Docência.

A partir do acompanhamento das formas de desenvolvimento do programa e suas possibilidades, a palavra qualidade foi buscada no documento da Fundação Carlos Chagas (FCC), sob responsabilidade de Gatti (2014), onde realiza a avaliação e o alcance dessa política pública direcionada à formação docente.

No quadro abaixo se observa as inúmeras vezes em que a palavra qualidade é utilizada se referindo à melhoria da qualidade da educação, seja da formação inicial dos professores, ou mesmo em relação à qualidade das práticas educativas. Urge nesse sentido, que nos perguntemos de qual qualidade o documento refere. 

\begin{tabular}{|l|l|l|l|l|}
\hline As bolsas e auxílios são concedidos mediante projeto de trabalho selecionado por sua & p. 10
\end{tabular} qualidade.
[...] o desenvolvimento profissional dos docentes de modo que estes possam contribuir p. 15 com uma educação de qualidade voltada às crianças e jovens que frequentam a escola.
\begin{tabular}{|ll}
\hline$[.$.$] categorias são apenas indicativos de importância e não se prestam a rankings, mas,$ & p. 26
\end{tabular} sim, ajudam a evidenciar ênfases em qualidades ou problemas.
\begin{tabular}{lll}
\hline Levantam ainda a questão que o programa propicia questionar construtivamente a qua- & p. 28
\end{tabular}
lidade das práticas formativas no âmbito da docência.
\begin{tabular}{|l|l|l|l}
\hline Tensão salutar no âmbito de cursos cuja qualidade formativa é vital para a sociedade... & p. 30
\end{tabular}

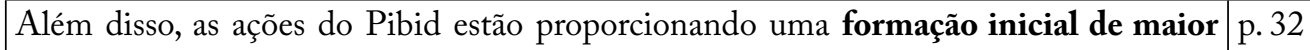 qualidade.

Fica cada vez mais patente que a despreocupação dessa dimensão tem sido responsável p. 33 não apenas pela má qualidade da educação em Nível Médio; [...] muitas vezes incapazes de ultrapassar com qualidade o âmbito mais restrito de seus estudos particulares \begin{tabular}{|l|l|}
\hline$[\ldots]$ a melhoria da qualidade dos cursos... & p. 34
\end{tabular} $\begin{array}{ll}\text { Para o curso de Licenciatura o projeto tem elevado a qualidade da formação dos nossos } & \text { p.35 }\end{array}$ alunos $[\ldots]$

[...] contribui para a elevação da qualidade do ensino e da formação p. 41 cultural dos alunos;

\begin{tabular}{|ll}
\hline$[.$.$] os percentuais são apenas indicativos de importância e não se prestam a rankings,$ & p. 47
\end{tabular} mas, sim, ajudam a evidenciarem fases em qualidades ou problemas.

$\begin{array}{ll}\text { O Pibid é importante e significativo para a formação profissional e contribui para a } & \text { p. } 48\end{array}$ elevação da qualidade dos cursos de formação inicial de professores e o enriquecimento do currículo;

Ao compromisso da universidade com o ensino público de qualidade.

[...] Sendo mais uma a contribuir com a melhoria da qualidade nas escolas e conse-
p. 51 quentemente a elevar o índice do Ideb.

Melhoria na qualidade da formação/melhoria da licenciatura;

Melhoria na qualidade do ensino e benefícios para a escola pública

\begin{tabular}{|l|l|}
\hline Melhorando a qualidade do profissional e, consequentemente, do ensino. & p. 55
\end{tabular}

Como referência de qualidade e melhoria em torno de sonhos profissionais e desenvolvimento educacional e social; Isto melhora a qualidade de ensino [...]. $\quad$ p. 56

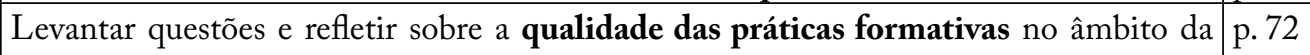

docência; Contribuindo assim para realizar um trabalho de qualidade nas escolas; Somando qualidade na formação

\begin{tabular}{|l|l|l}
\hline Possibilitou observaras transformações dos alunos quando adquirem um ensino de qua- & p. 73
\end{tabular} lidade [...]

Melhoria da qualidade do ensino e da aprendizagem; Melhoria da qualidade de for- p. 74 mação nas licenciaturas [...] 


\begin{tabular}{|c|c|}
\hline Oferecer ao aluno uma educação de qualidade[...] & p. 75 \\
\hline Aprimorando e incentivando a qualidade dos profissionais da educação. & p. 77 \\
\hline $\begin{array}{l}\text { Os alunos têm demonstrado melhoria na qualidade da aprendizagem da leitura e es- } \\
\text { crita }[\ldots]\end{array}$ & p. 80 \\
\hline $\begin{array}{l}\text { O programa propiciou melhoria na qualidade da assistência aos alunos com baixo } \\
\text { aproveitamento nos conteúdos curriculares. }\end{array}$ & p. 81 \\
\hline Melhoria na qualidade do ensino oferecido na escola. & p. 82 \\
\hline Contribuição para a melhoria da qualidade da educação básica [...] & p. 83 \\
\hline No sentido de melhorar a qualidade de suas aulas. & p. 84 \\
\hline [...] quer seja através do incentivo a uma formação inicial de qualidade [...] & p. 86 \\
\hline Melhoria da qualidade de ensino nas escolas; & p. 88 \\
\hline $\begin{array}{l}\text { [...] o fortalecimento da licenciatura e a melhoria da qualidade dos cursos, propiciada } \\
\text { pela articulação teoria-prática [...] }\end{array}$ & p. 89 \\
\hline $\begin{array}{l}\text { Comprometida com a qualidade e o desenvolvimento do ensino } \\
\text { nas escolas participantes do Programa e na Licenciatura em Educação do Campo. }\end{array}$ & p. 90 \\
\hline $\begin{array}{l}\text { Os efeitos do Pibid na qualidade do ensino oferecido nas escolas; Benefícios tanto para } \\
\text { a melhoria da qualidade dos cursos de licenciatura; [... ] quanto para a qualidade do } \\
\text { ensino nas escolas e [...] }\end{array}$ & p. 91 \\
\hline $\begin{array}{l}\text { uma formação com qualidade e criticidade daquele que irá interagir com as várias ge- } \\
\text { rações de aprendiz. }\end{array}$ & p. 92 \\
\hline objetivo de manter a qualidade do trabalho desenvolvido neste programa & p. 92 \\
\hline isica pública. & p. 98 \\
\hline Há melhorias na qualidade dos cursos, & p.104 \\
\hline $\begin{array}{l}\text { Ajuda a questionar construtivamente a qualidade das práticas formativas no âmbito da } \\
\text { docência na própria IES. }\end{array}$ & p.105 \\
\hline Há melhorias na qualidade do ensino $[\ldots]$ & p.105 \\
\hline $\begin{array}{l}\text { Verifica-se que sua metodologia de implementação ganhou em } \\
\text { qualidade, bem como na transparência de seus propósitos e quanto aos meios para }\end{array}$ & p.111 \\
\hline
\end{tabular}

Fonte: Adaptado pelo autor a partir de Gatti et al, 2014.

O quadro acima salienta a qualidade educacional sem indicar de qual qualidade se fala. Sendo qualidade apalavra central, Hattge (2014) traz a ideia de que reconhecemos a política educacional como produto de compromissos, articulados dentro de um contexto específico de grupos de interesse que "entende que essa qualidade está intimamente relacionada à produtividade, ao rendimento” (HATTGE, 2014, 10).

Assim, em acordo com Hattge (2014), tem-se que a educação enquanto performance que impera na contemporaneidade, está baseada em ideais advindas de estratégias do Banco Mundial (BM) e Programa das Nações Unidas para o Desenvolvimento (PNUD). Tal discurso está alicerçado em uma nova perspectiva de qualidade assentada na busca por melhores desempenhos em avaliações de larga escala, dando ênfase à 
qualidade da educação que passa a ser "numerável, mensurável, audível” (HATTGE, 2014, 10).

Naturalmente, é preciso pensar no papel dos Organismos Multilaterais, nas discussões que envolvem o delineamento da qualidade da educação por meio das políticas que, cada vez mais atreladas a seus projetos e programas, produz estudos e documentos orientadores para a política educacional brasileira.

Nos últimos anos organismos multilaterais como a UNESCO e o Banco Mundial participam ativamente com apoio técnico e elaboração de projetos educativos em países em desenvolvimento. No que tange às discussões das últimas décadas de 1980 e 1990, a Organização para a Cooperação e Desenvolvimento Econômico (OCDE), Comissão Econômica para América Latina e Caribe (CEPAL), Programa das Nações Unidas para o Desenvolvimento (PNUD) e Fundo das Nações Unidas para a Infância (UNICEF), têm participado mais ativamente desse processo (DOURADO, et al, 2007, p. 9).

Documentos da CEPAL abordam a qualidade da educação enfatizando a necessidade do desenvolvimento de ferramentas e diagnósticos por meio de provas ou instrumentos de aferição da qualidade. De acordo com Dourado, et al (2007) "[...] para a Cepal, a avaliação é fundamental para o monitoramento das políticas e para orientar as intervenções no campo educativo" (p. 10).

Já a Organização das Nações Unidas para a Educação, a Ciência e a Cultura (UNESCO) e a Oficina Regional de Educación para América Latina y el Caribe(OREALC) compreendem a qualidade da educação como um fenômeno complexo e multifacetário, o qual deve ser compreendido por diversas perspectivas, apontando principalmente para quatro dimensões: pedagógica, cultural, social e financeira. Ressalta-se que a Unesco sinaliza que uma educação de qualidade é aquela que contribui para a equidade (UNESCO/OREALC, 2002, 2003).

Outro organismo multilateral fundante nesse processo é o Banco Mundial (BM), tendo sua concepção voltada à qualidade da educação mensurada pela eficiência e eficácia dos sistemas educativos, sobretudo por meio da mediação de processos de ensino e aprendizagem (CASAGRANDE, 2014). Os projetos financiados pelo Banco centram-se na expansão do acesso, na qualidade e eficiência interna e de uma dada concepção de qualidade para as diretrizes de currículos, para a formação de professores, avaliação de impactos de programas o que inclui as abordagens para melhoria da qualidade dos professores, das taxas de repetição, das distorções idade-ano, além do descontrole da qualidade do Ensino Médio.

Portanto, a ciência de que a abordagem da questão da qualidade na educação envolve inúmeras dimensões remete a uma busca de compressão que perpassa por elementos subjetivos e objetivos, os quais nos posicionam no interior desse debate, em relação às nossas percepções da vida escolar, bem como em relação às percepções dos demais sujeitos envolvidos na organização da escola, ou mesmo na elaboração de importantes programas como é o caso do PIBID. 
A inserção da questão da qualidade da educação básica em relação às possíveis apropriações dos professores/acadêmicos/ bolsistas durante o percurso de sua atuação, implica em dupla responsabilização: uma pelo fracasso da aprendizagem docente e, outra, pela ausência de aprendizagem dos alunos, que em última instância desconhece as interfaces da política de formação de professores oferecida àquele que o ensina. Por este alcance tem-se a dimensão do cárcere em que vivem e se implementam políticas educacionais.

\section{CONCLUSÃO}

Como se observou, as novas configurações da formação docente e do que é esperado do professor têm feito parte de um rol de "re-trabalhos", como forma de proporcionar melhorias para a qualidade da educação, não escapam do feito até mesmo os empreendedores educacionais, tais como, gestores "sujeitos as avaliações/apreciações regulares, a revisões e comparações do seu desempenho. Novas formas de disciplina são colocadas pela competição, eficiência e produtividade" (Ball, 2002, p. 7). Assim, quando nos referimos à qualidade da educação, devemos levar em conta os fatores intra e extraescolares que fazem referência às condições de vida dos alunos, no seu contexto de vida social, cultural e econômica, bem como da própria escola, dos professores, diretores, etc., tendo em vista as relações intersubjetivas presentes quando subordinadas ao controle do capital, pois tendem a criar modelos de formação, políticas emergenciais sem garantir a qualidade que tanto apregoa.

Assim é mister compreender que,

[...] a qualidade da educação é um fenômeno complexo, abrangente, e que envolve múltiplas dimensões, não podendo ser apreendido apenas por um reconhecimento de variedade e das quantidades mínimas de insumos considerados indispensáveis ao desenvolvimento do processo ensino-aprendizagem e muito menos sem tais insumos (...). Desse modo, a qualidade da educação é definida envolvendo a relação entre os recursos materiais e humanos, bem como a partir da relação que ocorre na escola e na sala de aula [...] (DOURADO, OLIVEIRA E SANTOS, 2007, p. 9).

Em sintonia com essas perspectivas a melhoria da qualidade da educação brasileira não deve ser somente função do Programa Institucional de Bolsas de Iniciação à Docência, (e sabemos que não é dessa forma que acontece), mas não compete salientar que para a melhoria é preciso que exista um regime de colaboração entre a União, Estados, Distrito Federal e Municípios, que objetive de fato assegurar o acesso e permanecia dos alunos neste ambiente público (escolas).

Nesse sentido, a qualidade da educação revela, também uma escola eficaz como resultado de uma construção de sujeitos engajados pedagogicamente, tecnicamente e politicamente no processo educativo, o que, por vezes, pese as condições objetivas de ensino, desigualdades sócio econômicas, cultural dos alunos, a desvalorização 
profissional dos professores. Todavia é importante destacar que "os trabalhadores em educação, (juntamente com os alunos e pais), quando participantes ativos, são de fundamental importância para a produção de uma escola de qualidade ou escola que apresenta resultados positivos em termos de aprendizagem" (DOURADO et al, 2007, p. 8).

Temos percebido em alguns estudos realizados sobre a política educacional brasileira, uma nova forma de cultura da performatividade competitiva, que tem envolvido os programas voltados à formação docente, advinda de uma "teoria econômica recente como também de varias práticas industriais que "ligam a organização e $o$ desempenho das escolas aos seus ambientes institucionais" (BALL, 2002, p. 7).

De acordo com Ball,

\begin{abstract}
No novo mundo das organizações performáticas o poder instituído segundo formas definidas de tempo-espaço (sistemas de produção de fabricas ou escritórios) é agora menos importante. A base de dados, a reunião de avaliação, a revisão anual, a redacção de relatórios e a candidatura a promoções, inspecções e comparação com pares estão em primeiro plano (BALL, 2002, p. 9).
\end{abstract}

Nestas condições, somos constantemente classificados por meio de tabelas, recebemos prêmios, somos admitidos em algum lugar por meio de procedimentos específicos de aprovação,

[...] somos classificados em pequenos catálogos escolares e acadêmicos, em artigos de jornal, em softwares de avaliação, em sistemas de avaliação e de medição da nossa performance, em padrões de referência e em metas. Isto é a neoliberalização. Esta é a parafernália, esses aparatos que nos reconstroem as nossas práticas. (BALL, 2013, s/p)

Ball ainda complementa, nos dizendo que "[...] um modelo sociocultural que reconhecia e incluía os aspectos emocionais e sociais necessários para uma abordagem mais 'centrada no aluno', não tem lugar no mundo produtivo da performatividade. $\mathrm{O}$ efetivo está comprometendo o afetivo" (BALL, 2005, p. 553,) e todas as circunstâncias que envolvem o processo de ensino-aprendizagem.

Sobretudo se pensarmos que, no seio da estrutura da performatividade, temos a organização enquanto poder e acordo de formas definidas, pois, se instaura a cultura da performatividade competitiva que "envolve uma combinação de descentralização, alvos e incentivos para produzir novos perfis institucionais que 'envolve uma combinação de descentralização, alvos e incentivos para produzir novos perfis institucionais"” (Ball, 2004, p. 1104)

Tais observações nos levam a compreender que não é mais possível vermos as políticas educacionais apenas no âmbito do Estado-Nação, mas sim por como um assunto de cunho regional e principalmente global, cada vez mais afinado com assuntos 
de comércio internacional. A educação em vários sentidos no mundo contemporâneo é vista como uma oportunidade de negócios (BALL, 2004).

A performatividade segundo Ball,

[...] desempenha um papel crucial nesse conjunto de políticas. Ela funciona de diversas maneiras para "atar as coisas" e reelaborá-las. Ela facilita o papel de monitoramento do Estado, "que governa a distância" - "governando sem governo". Ela permite que o Estado se insira profundamente nas culturas, práticas e subjetividades das instituições do setor público e de seus trabalhadores, sem parecer fazê-lo (BALL, 2004, p. 1116).

Desse modo trata-se de pensarmos que ela (performatividade) "indica", muda significados, produzem novos e variados perfis, produz "alinhamento", objetificam, "mercantiliza o trabalho do setor público, das instituições educativas, transformando-as em "resultados", "níveis de desempenho", formas de "qualidade" (BALL, 2004, p. 1116, grifos nossos). Neste sentido, se torna fundamental observar que a performatividade que condiciona, controla e subverte para atender o controle social. Pode também abrir espaços para discussão e para proposições para sair desse circuito empobrecido de qualidade educacional. Há que se lutar por uma formação humano histórica e cultural, o que inclui conhecimento de toda a ordem e que foi produzido pela humanidade e que é direito de todos.

\section{REFERÊNCIAS}

ANDRÉ, M . E. D. A Programas e políticas de inserção à docência em estados e municípios brasileiros: um dilema na formação de professores, 2012, Campinas. Anais do XVI ENDIPE - Encontro Nacional de Didática e Práticas de Ensino. UNICAMP, Campinas, 2012.

ANDRÉ, M . E. D. A. Departamento de Educação Básica. Relatório de gestão 20092014. Vol1.; Brasília: CAPES, 2015. Disponível em: <http://www.capes.gov.br/images/ stories/download/bolsas/20150818_DEB-relatorio-de-gestao-vol-1-com-anexos.pdf $>$. Acesso em: 21 dez. 2017.

BALL, S. J. Profissionalismo, gerencialismo e performatividade.Cadernos de. Pesquisa. vol.35, n.126, 2005. p.539-564.

BALL, S. J. Reformar escolas/reformar professores e os terrores da performatividade. Revista Portuguesa de Educação, Braga, v. 15, n. 2,2002. p. 3-23.

BALL, S. J. Performatividade, privatização e o pós-Estado do Bem-Estar. Educ. Soc. [online]. 2004, vol.25, n.89, pp.1105-1126.ISSN 0101-7330. http://dx.doi.org/10.1590/S010173302004000400002 .

BANCO MUNDIAL. Prioridades y estratégias para La educación: Examen del Banco Mundial, Washington: DC., 1996. 
BERNSTEIN, B. A estrutura do discurso pedagógico: classes, códigos e controle. Petrópolis: Vozes. Brasil. (2009).

BRASIL. Portaria normativa no 16, de 23 de dezembro de 2009. Dispõe sobre o PIBID - Programa Institucional de Bolsa de Iniciação à Docência. Diário Oficial da República Federativa da Brasil, Brasília, 24 de dezembro. Seção 1, p. 92, 1996.

BRASIL. Coordenação de Aperfeiçoamento de Pessoal de Nível Superior. Portaria no 096, de 18 de julho de 2013 do Programa Institucional de Bolsa de Iniciação à Docência PIBID. CAPES: Brasília, 2013.

CASAGRANDE, I. M. K.; Pereira, S. M. y Sagrillo, D. R. O Banco Mundial e as políticas de formação docente no Brasil. ETD - Educação Temática Digital, Campinas, SP, v. 16, n. 3, 2014. p. 494-512, set./dez. ISSN 1676-2592. http://dx.doi.org/10.20396/etd.v16i3.1311.

DOURADO, L.F.; Oliveira, J.F. y Santos, C. A. A qualidade da educação: conceitos e definições. Brasília, DF: INEP, 2007.

EVANGELISTA, O. (Org.). O que revelam os slogans na política educacional. Araraquara: Junqueira\&Marin Editores, 2014.

GATTI, B. A. et al. Um estudo avaliativo do Programa Institucional de Bolsa de Iniciação à Docência (Pibid). São Paulo: Fundação Carlos Chagas/SEP, 2014.

HATTGE, M. D. A emergência da performatividade na educação brasileira:uma análise do movimento Todos Pela Educação. Anais... X ANPED SUL, Florianópolis, 2014. Disponível em: <http://xanpedsul.faed.udesc.br/arq_pdf/956-0.pdf〉. Acesso em: 20 dez. 2017.

JARDILINO, J.R.L. Políticas de formação de professores em conflito com o currículo: estágio supervisionado e PIBID. Educação, v. 39, n. 2, p. 353-366, 2009.

JUNIOR. C. A. da S. Apresentação. In: Spazziani, M. de L. Profissão Professor: cenários, tensões e perspectivas. São Paulo: Editora Unesp. 2016.

LIMA, S. M. de. Aprender para ensinar, ensinar para aprender: aprende-se no curso de pedagogia? Cuiabá: EdUFMT, 2007.

LYOTARD, J. F. The Postmodern condition: a report on knowledge.10. Manchester: Manchester University Press, 1984.

NÓVOA, A. Formação de professores e profissão docente. In: Nóvoa, A. (org.). Os professores e a sua formação. Lisboa: Publicações Dom Quixote, 1992

PAREDES, G. G. O. Um estudo sobre o PIBID: saberes em construção na formação de professores de Ciências, 2013. Dissertação (Mestrado em Educação em Ciências e Matemática) Universidade Federal do Paraná. Curitiba, 2013.

SHIROMA E. O.; Campos, R. F. y Garcia, R. M. C. Decifrar textos para compreender a política: subsídios teórico-metodológicos para análise de documentos. Perspectiva, Florianópolis, v. 23, n. 02, 2005 p. 427-446, jul./dez. 
TOBALDINI, B. G. Os saberes docentes na formação de professores: o caso do programa institucional de bolsa de iniciação a docência (PIBID) subprojeto química/UFPR 2010/2012. Dissertação (Mestrado). Universidade Federal do Paraná, Curitiba, 2013.

UNESCO. Laboratório Latinoamericano de Evaluación de La Calidad de La Educación. Estudio cualitativo de escuelas con resultados destacables em siete países latino-americanos. Santiago de Chile, septiembre, 2002. Disponível em: <http://unesdoc.unesco.org/ images/0013/001310/131037s.pdf>. Acesso em: 19 dez. 2017.

UNESCO. Proyecto Regional de Indicadores Educativos. Alcanzando las metas educativas: Informe Regional. Santiago de Chile, 2013. 